\title{
Ensemble Forecasting of Volcanic Emissions in Hawai'i
}

\author{
Andre Pattantyus ${ }^{1 *}$, Steven Businger ${ }^{1}$ \\ 1 University of Hawaii at Manoa, USA \\ *akp4221@hawaii.edu
}

\begin{abstract}
Deterministic model forecasts do not convey to the end users the forecast uncertainty the models possess as a result of physics parameterizations, simplifications in model representation of physical processes, and errors in initial conditions. This lack of understanding leads to a level of uncertainty in the forecasted value when only a single deterministic model forecast is available. Increasing computational power and parallel software architecture allows multiple simulations to be carried out simultaneously that yield useful measures of model uncertainty that can be derived from ensemble model results. The Hybrid Single Particle Lagrangian Integration Trajectory and Dispersion model has the ability to generate ensemble forecasts. A meteorological ensemble was formed to create probabilistic forecast products and an ensemble mean forecast for volcanic emissions from the Kilauea volcano that impacts the state of Hawai'i. The probabilistic forecast products show uncertainty in pollutant concentrations that are especially useful for decision-making regarding public health. Initial comparison of the ensemble mean forecasts with observations and a single model forecast show improvements in event timing for both sulfur dioxide and sulfate aerosol forecasts.
\end{abstract}

\section{INTRODUCTION}

$\mathrm{T}$ he Kilauea volcano has been continuously erupting from the $\mathrm{Pu}^{\prime} \mathrm{u}$ 'O'o vent (East Rift vent) since 1983, emitting large amounts of sulfur dioxide $\left(\mathrm{SO}_{2}\right)$. The rate of emissions has ranged from less than 50 tonnes/day to more than 10,000 tonnes/day [Elias and Sutton, 2007]. In 2008, a second vent opened up in the Halema'uma'u Crater (summit vent) with a typical emission rate of $\sim 700$ to 1000 tonnes/day based on in-situ observations. Photochemical and aqueous-phase reactions convert $\mathrm{SO}_{2}$ to sulfates $\left(\mathrm{SO}_{4}\right)$. Together the $\mathrm{SO}_{2}$ and sulfate aerosol form a plume of pollution known as "vog" after volcanic smog.
Prevailing northeast trade winds in Hawaii advect the emissions downwind past the south end of the Island of Hawai'i where a sea breeze circulation brings the vog to leeward communities, causing frequent episodes of poor air quality. Longo [2013] found the magnitude of health effects increasing relative to exposure levels following the opening of the Halema'uma'u vent. Southerly flow, also known in Hawaii as kona wind conditions, which occur most frequently in the winter months (OctMar), bring the vog plume over the village of Volcano, only $4 \mathrm{~km}$ from the vent. The close proximity of Volcano to the vent exposes its inhabitants to dangerously high concentrations of vog during kona conditions, leading to 
ANNALS OF GEOPHYSICS, Fast Track 2, 2014

evacuation orders in the recent past.

An automated numerical model approach has been implemented at the University of Hawai' $i$ at Manoa (UHM) to forecast the dispersion of emissions from Kilauea volcano across the Island of Hawai' $i$ and the other main Hawaiian islands [Hollingshead et al., 2003]. The goal of the modeling effort is to give useful forecast guidance regarding the location of the vog plume and the concentrations of sulfur dioxide and sulfate aerosol in Hawaiian Island communities in a timely manner.

The UHM Vog Model is a custom application of the HYbrid Single-Particle Lagrangian Integration Trajectory (HYSPLIT) and dispersion model [Draxler and Hess, 1997; 1998]. The Vog model has been operational since 2010 and produces $60-\mathrm{hr}$ forecasts twice daily for sulfur dioxide and sulfate aerosol concentrations at $100 \mathrm{~m}$ above ground level. The model resolution is determined by the meteorological grids from the Weather Research and Forecasting (WRF) model. Emission rate data are estimated from an array of UV FLYSPEC spectrometers [Horton et al., 2006] near the summit vent as well as a car-mounted FLYSPEC that samples both emission plumes. Sulfur dioxide emissions are specified as vertical line sources at each vent to mimic plumes under typical trade wind conditions.

There is a growing trend to move away from purely deterministic simulations to probabilistic simulations where modelers seek to describe the range of likely events and their associated probabilities [Dabberdt and Miller, 2000]. Model uncertainties commonly occur through excessive simplification of physical processes in the model, i.e. turbulence, or the misrepresentation of the meteorological conditions that can result from inadequate spatial data resolution, sampling errors, or inclusion of unrepresentative observations. Even with further improvements to the vog model, underlying model bias still remains in deterministic forecasts due to physical parameterizations or simplifications and model numeric schemes that convey a sense of certainty that is not always supported by the model. Pollutant prediction uncertainty information may be especially critical for economic decisions, regulatory applications, and human health issues, especially for the atmospheric release of hazardous materials [Draxler, 2003].

Probabilistic forecasts are developed by building ensembles of model simulations to calculate the model mean or median values and model variance. Experimental vog model ensemble forecast products have been developed. It is important to note that an ensemble can only give significant improvements if participating models have complementary strengths and weaknesses, and therefore are representative of the uncertainty in our knowledge [van Loon et al., 2007]. In this respect, the ensemble described in this paper is lacking complementary models as it relies entirely on initial and lateral boundary conditions provided by WRF forecasts. Thus any weaknesses in the WRF forecasts will be manifest in the vog forecasts via the meteorological forcing.

\section{METHODS}

Although sulfur dioxide emission uncertainty is significant, emissions are subject to meteorological conditions, such as stability, turbulence, and winds, that are primarily responsible for what areas are affected by poor air quality. A meteorological ensemble strategy has been applied in the vog model. The ensemble is well suited for conditions around the Halema'uma'u Crater. It is well known that only meteorological features that are sampled by $5 x$ grid points are well resolved in observations and in numerical models [Carbone et al., 1985]. Since the vog model has a $1.0 \mathrm{~km}$ grid 
spacing, localized flow patterns that have been observed through plume motions around the summit crater $(\sim 1.0-2.0 \mathrm{~km})$ are unresolved by the model. This ensemble addresses the uncertainty in the under-sampled meteorological fields near the vent sites.

The assumption behind the meteorological ensemble is that errors in the downwind plume position are primarily a function of the accumulation of initial errors in the particle trajectories [Draxler, 2003]. This is analogous to differences in initial conditions in which errors are largest just downwind of the source. The ensemble consists of 27 equally-weighted members. Each ensemble member is computed from the same pollutant source location(s), but during the calculation the meteorological grid is offset by \pm 1 grid point $(1.0$ $\mathrm{km})$ in the horizontal direction and $.01 \%$ the depth of the vertical grid $(\sim 20 \mathrm{~m})$ in the vertical direction (Table 1). The exact computational procedure is explained in detail by Draxler [2003]. While model outliers may impact the ensemble results when all models have equal weights, correcting for this requires a larger data set than is presently available for this study. Once the ensemble is run, the results must be summarized and displayed graphically in a manner easily understood by the end user of the model guidance. The vog model post-processing calculates the ensemble mean concentration values presented in this study. The ensemble mean has been shown to outperform any single model [van Loon et al., 2007 and references within]. It is important for the ensemble model uncertainty for the forecast be conveyed graphically as well.

Draxler [2003] developed a probabilistic air quality forecast product around exceedance factors following the work of Krzysztofowicz [1998] for quantitative precipitation forecasts (QPF). These probability exceedance (PE) plots are representations of the probability of exceeding a specific concentration level at the $\mathrm{n}^{\text {th }}$-percentile values.

Table 1: List of HYSPLIT ensemble members and their grid offsets. Model 10, with no grid offsets, is closest to the operational model configuration. Adapted from Draxler [2003].

\begin{tabular}{l|lll}
\hline Member & $\mathrm{X}$ & $\mathrm{Y}$ & $\mathrm{Z}$ \\
\hline 1 & 0 & 0 & -1 \\
2 & 0 & +1 & -1 \\
3 & 0 & -1 & -1 \\
4 & +1 & 0 & -1 \\
5 & +1 & +1 & -1 \\
6 & +1 & -1 & -1 \\
7 & -1 & 0 & -1 \\
8 & -1 & +1 & -1 \\
9 & -1 & -1 & -1 \\
10 & 0 (control) & 0 & 0 \\
11 & 0 & +1 & 0 \\
12 & 0 & -1 & 0 \\
13 & +1 & 0 & 0 \\
14 & +1 & +1 & 0 \\
15 & +1 & -1 & 0 \\
16 & -1 & 0 & 0 \\
17 & -1 & +1 & 0 \\
18 & -1 & -1 & 0 \\
19 & 0 & 0 & +1 \\
20 & 0 & +1 & +1 \\
21 & 0 & -1 & +1 \\
22 & +1 & 0 & +1 \\
23 & +1 & +1 & +1 \\
24 & +1 & -1 & +1 \\
25 & -1 & 0 & +1 \\
26 & -1 & +1 & +1 \\
27 & -1 & -1 & +1 \\
\hline
\end{tabular}

In such a plot, only one concentration threshold is considered with multiple probability levels. The output can be displayed as a 
concentration-probability (CP) plot, where concentration contours are plotted at a specific probability level. This type of plot portrays a range of thresholds at a single probability level.

\section{RESULTS}

A Kona wind event on 21 November 2013 is used to illustrate the results of an ensemble simulation over Hawai' i. As expected, the vog model results for this case suggest that concentrations for sulfur dioxide (Fig. 1) and sulfate aerosols (Fig. 2) are more likely to be exceeded in close proximity to and downwind of the vent source locations and that higher thresholds are more likely to be exceeded in this region as well. The orography of the Island of Hawai' $i$ and the trade wind inversion play a significant role in constraining where the probability of experiencing vog is greatest. The trade wind inversion at 2,200 m causes the vog to be trapped $\left(\mathrm{F}_{\mathrm{r}}=.17\right)$ and is advected by weak southerly flow around the higher terrain. The ensemble shows the pollutants are concentrated below the inversion as was seen by Hollingshead et al. [2003]. CP maps (Fig. 3) also imply that the village of Volcano, located just north of the source vents, is most likely to encounter seriously unhealthy vog concentrations during this event.

Validation of the ensemble mean is necessary to determine the added value of ensemble forecasts over a single model forecast. The ensemble mean is compared against observations and the results from the control run of the operational model (Fig. 4), which has no displacement of the wind field (c. f. Table 1).

Pollution episodes are defined by the sulfur dioxide observations because the sulfate aerosol observations are actually PM2.5 aerosol observations that include aerosols other than sulfate, such as sea salt particles, pollen, dust, and in- dustrial and vehicular emissions.

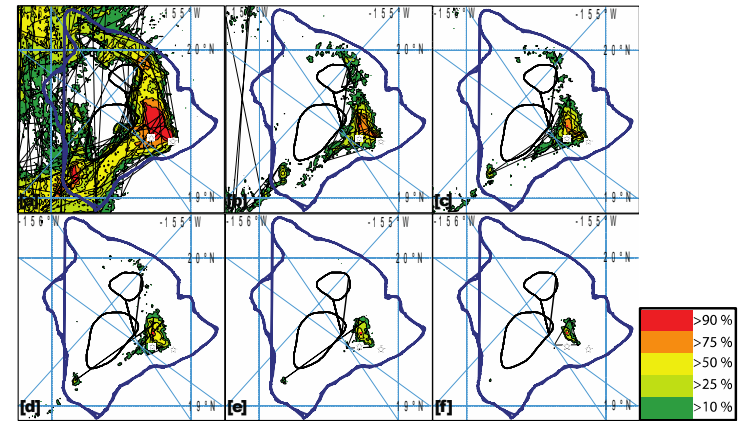

Figure 1: Probability of exceedance (PE) maps for $\mathrm{SO}_{4}$ levels at [a] 1E-8 $\mu \mathrm{g} / \mathrm{m}^{3},[b] 15 \mu \mathrm{g} / \mathrm{m}^{3},[\mathrm{c}] 35 \mu \mathrm{g} / \mathrm{m}^{3},[d]$ $65 \mu \mathrm{g} / \mathrm{m}^{3}$, [e] $150 \mu \mathrm{g} / \mathrm{m}^{3}$, and [f] $250 \mu \mathrm{g} / \mathrm{m}^{3}$ valid for period 1600-1700 HST 21 November 2013. Thresholds conform to Airnow.gov's Air Quality Index for PM2.5 (sulfate) exposure. The stars denote the source locations, volcanic vents. The heavy black lines represent the 2,200 $m$ height contour.

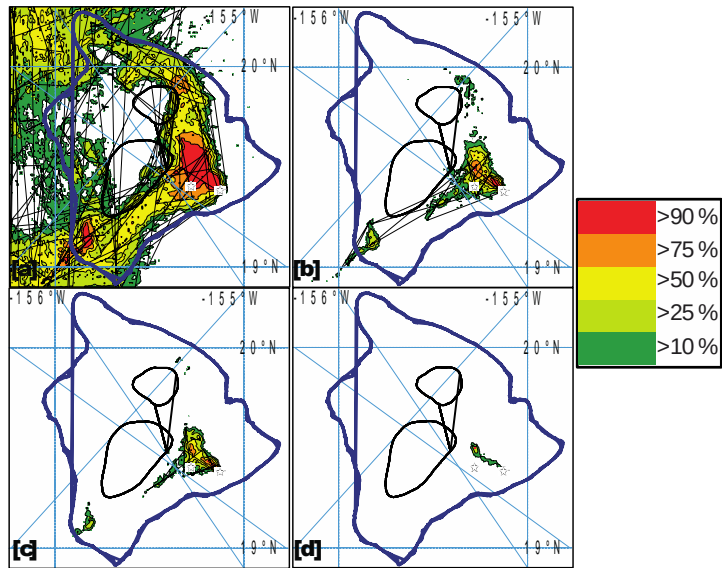

Figure 2: Probability of exceedance (PE) maps for $\mathrm{SO}_{2}$ levels at [a] 1E-6 PPM, [b] 0.1 PPM, [c] 0.2 PPM, and [d] 1.0 PPM valid for period 1600-1700 HST 21 November 2013. Thresholds conform to Hawai'I Department of Health guidelines for sulfur dioxide exposure. $\mathrm{SO}_{2}$ maps do not exist for higher concentrations because sulfur dioxide oxidizes rapidly in moist environments to form sulfates $\left(\mathrm{SO}_{4}\right)$. The stars denote the source locations, volcanic vents. The heavy black lines represent the 2,200 m height contour. 


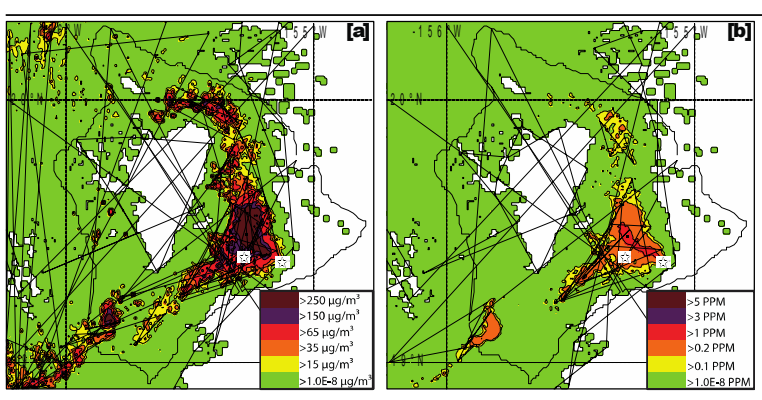

Figure 3: Concentration-probability maps at the $95^{\text {th }}$ percentile level for [a] $\mathrm{SO}_{4}$ and [b] $\mathrm{SO}_{2}$ for the same time periods as in Figures 1 and 2. The threshold levels and color table for $\mathrm{SO}_{2}$ correspond to Hawai'i Department of Health standards and those of $\mathrm{SO}_{4}$ correspond to PM2.5 levels established by the EPA. Within a contour, $5 \%$ of the members (2 of 27) predict a higher concentration than the one given by the contour, and outside of it, $95 \%$ of the models in the ensemble (25 of 27) predict a lower concentration.

These episodes are resolved well. The ensemble tends to capture both onset and cessation better than the control. There is a large positive forecast bias in maximum values for the ensemble and control, which is partially a result of emission initialization (i.e. multi-day average emission estimates) and model chemistry. These are issues that we are in the process of addressing.

\section{DiscusSION}

In summary, preliminary results of this single case suggest that the ensemble mean forecasts will improve the pollution episode representation for locations on the Island of Hawai'i. Probabilistic air quality forecasts provide additional information for improved decision-making, regulatory purposes, and risk management, especially for public health. Levels of confidence can be assigned to particular forecast events to help reduce false alarms. Probability exceedance (PE) maps display the ensemble derived probability information in the most readily understood format.
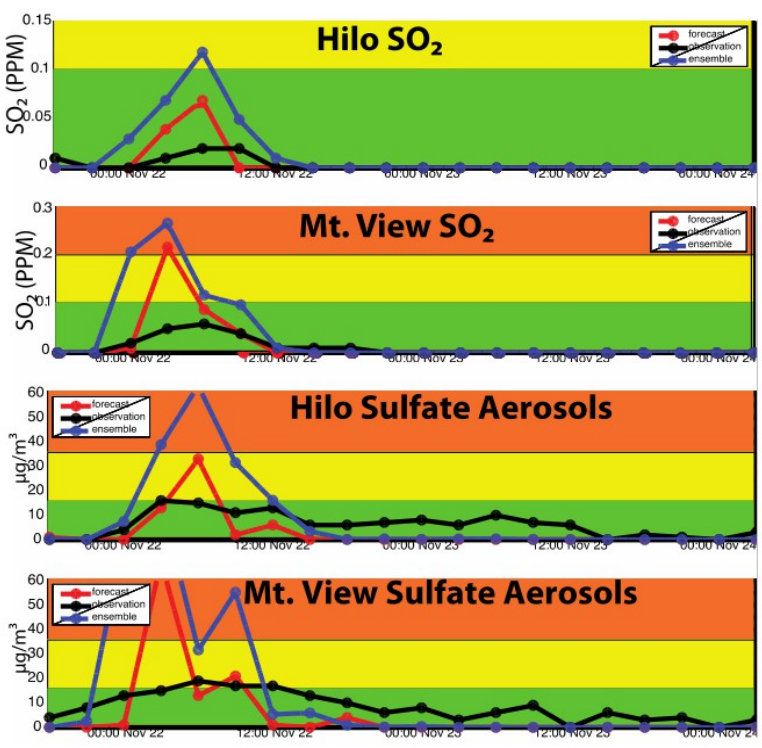

Figure 4: Sulfur dioxide and sulfate aerosol $\left(\mathrm{SO}_{4}\right)$ timeseries for locations downwind of the vog sources (Mountain View and Hilo). Background colors reflect the threshold values shown in Figure 3. Observations for sulfate aerosol actually fall under PM2.5, so values reflect constituents other than sulfate.

A comprehensive model ensemble includes the greater variability displayed by several independent modeling systems, with differing initial conditions and physics schemes. The current ensemble instead simulates the inherent variability of the wind field by shifting the WRF model high-resolution output relative to the emission source. In cases where there are errors in the initial conditions of WRF, the observed evolution of the wind field may fall outside the variability seen in our WRF ensemble. A multi- mesoscale model ensemble may contain greater variability in the wind field and be more likely to capture the observed wind field evolution, however, it would be prohibitively expensive to run and the actual atmospheric evolution may still fall outside of such an ensemble during times of weak synoptic forcing (i.e. kona wind conditions).

The results of this case study also suggest that 
more work is needed to improve the deterministic and ensemble vog models. A full validation effort will be conducted after improvements to the vog model are completed. In particular an improved chemistry module is being developed for the conversion of $\mathrm{SO}_{2}$ to sulfate aerosol and a plume-rise model is being developed to improve the initial source of emissions.

\section{ACKNOWLEDGEMETS}

All data used in this paper are archived locally and are available upon request. The authors would like to thank the reviewers for providing constructive feedback on this manuscript. The authors would like to thank Roland Draxler for his help producing the probability plots. The authors would like to thank Nancy Hulbirt who helped draft the final figures. The research was supported by the USGS under grant number G10AC00035.

\section{REFERENCES}

[Carbone et al., 1985] Carbone, R.E., Carpenter, M.J., Burghart, C.D. (1985). Doppler radar sampling limitations in convective storms. J. Atmos. and Ocean. Tech., 2:357-361.

[Dabberdt and Miller, 2000] Dabberdt, W. F. and Miller, E. (2000). Uncertainty, ensembles and air quality dispersion modeling: applications and challenges, Atmos. Environ., 34: 4667-4673.

[Draxler, 2003] Draxler, R. R. (2003). Evaluation of an Ensemble Dispersion Calculation, J. App. Meteor., 42:308-317.

[Draxler and Hess, 1997] Draxler, R. R. and Hess, G. D. (1997). Description of the HYSPLIT_4 modeling system. NOAA Tech. Memo. ERL ARL-224, NOAA Air Resources Laboratory, Silver Spring, MD, 24 pp.

[Draxler and Hess, 1998] Draxler, R. R. and Hess G. D. (1998). An overview of the HYS-
PLIT_4 modeling system of trajectories, dispersion, and deposition, Aust.Meteor. Mag., 47:295-308.

[Elias and Sutton, 2007] Elias, T. and Sutton, A. J. (2007). Sulfur dioxide emission rates from Kilauea Volcano, Hawai'i, an update: 20022006, U.S.Geol.Surv.Open-File,Rep.2,007-1,114. [Hollingshead et al., 2003] Hollingshead, A., S. Businger, R., et al. (2003). Dispersion modeling of the Kilauea plume. Bound.-Layer Meteor., 108:121-144.

[Horton et al. 2006] Horton, K.A., G. Williams-Jones et al. (2006). Real-time measurement of volcanic $\mathrm{SO} 2$ emissions: Validation of a new UV correlation spectrometer (FLYSPEC). Bull. Volcanol., 68: 323 - 327.

[Krysztofowicz, 1998] Krzysztofowicz, R. (1998). Probabilistic hydrometeorological forecasts - toward a new era in operational forecasting, Bull. Amer. Meteor. Soc., 79:243-251.

[Longo, 2013] Longo, B. M. (2013). Adverse Health Effects Associated with Increased Activity at Kilauea Volcano: A Repeated Population-Based Survey, ISRN Public Health, doi:10.1155/2013/475962.

[van Loon et al., 2007] van Loon, M., Vautard, R. et al. (2007). Evaluation of long-term ozone simulations from seen regional air quality models and their ensemble, Atmos. Environ., 41:2083-2097. 